\title{
Orthognathic surgery as part of pre prosthetic mouth preparation
}

\author{
Authors \\ Pulkit Jain $^{1}$, Shuja Ur Rahman ${ }^{2}$, Khurshid A Mattoo ${ }^{3} *$, Vishal Bansal ${ }^{4}$ \\ ${ }^{1}$ Ex Postgraduate Student, Department of Prosthodontics, Subharti Dental College, SVSU \\ ${ }^{2}$ Senior Lecturer, Department of Prosthodontics, Kothiwal Dental College, MJPRU \\ $3 *$ Assistant Professor, Department of Prosthodontics, College of Dentistry, Jazan University \\ ${ }^{4}$ Professor and Head, Department of Oral and Maxillofacial Surgery, Subharti Dental College, SVSU \\ *Corresponding Author \\ Khurshid A Mattoo
}

\section{Abstract}

There is rarely any treatment in dentistry which can be successful if prior mouth preparations are not conducted. In the field of prosthodontics, the targeted objectives of treatment cannot be achieved unless existing occlusion is not compatible with the components of a stomatognathic system. Skeletal malformations that result in protruded maxilla or mandible result in an ineffective occlusion that cannot perform most of its normal functions including the protection of the entire stomatognathic system. We present a case report of a young female who presented with a severe class 2 skeltal malocclusion. Orthognathic surgery was performed to place the maxilla posteriorly so that the anterior open bite is correct and anterior guidance becomes effective to protect the posterior teeth during protrusion.

Keywords: malocclusion, orthognathic surgery, osteotomy, Lefort level.

\section{Introduction}

Apertognathia (Latin apertus: Open; Greek gnathos: Jaw) is a term that refers to an excessive divergence of the maxillary, occlusal and mandibular planes in relation to each other and to the anterior cranial base and is a result of a hyperdivergent facial growth pattern. ${ }^{1,2}$ One of the key feature in such cases is the presence of an anterior open bite (AOB) which is the presence of a vertical space between the maxillary and the mandibular incisor teeth when the posterior teeth are in occlusion. ${ }^{3}$ Overlapping of components in etiology renders $\mathrm{AOB}$ as a clinical challenge for orthodontist, surgeon and prosthodontist. Although it's easily correctable when AOB is purely dental in origin, the problem is complexed when the etiology is skeletal and surgical intervention is must in such cases. ${ }^{4}$
Irrespective of the cause, AOB has short term and long term implications in occlusal functioning. Aesthetic, phonetic, functional (swallowing), mastication, psychological impairment in child development is immediate effects while most of them are long term. Due to abnormal tooth positions, development of periodontal diseases is also a common complication.,

Non correction of skeletal open bite has its own implications during correction of occlusion by prosthodontic fixed restorations like a single crown or a fixed partial denture. Absence or presence of an abnormal anterior guidance does not allow a prosthetic restoration to be functionally competent. Correction of anterior open bite in such cases is mandatory. This article in the form of a case report presents a case of preprosthetic surgical correction 
of a skeletal open bite case which was planned as part of a long term management for the preservation of natural dentition. The surgical correction was also planned to overcome the psychological impairment that the patient had developed over a period of time.

\section{Case Report}

A young female patient aged 26 years reported to the department of prosthodontics for replacement of a mandibular left first molar. The patient had developed an abscess in relation to the mandibular left first molar about 8 months back following which the tooth was extracted by a local dentist. Patients medical history was noncontributory. Social history disclosed patient was a very shy person and was not socially active since she claimed to have been bullied for her appearance since she was a child. Extra oral examination disclosed a severely prognathic maxilla (Fig 1a) with retruded mandible. Facial profile was severely convex and maxillary anterior and mandibular anterior teeth were severely proclined (Fig 1b). A diagnostic impression was made at this stage and the casts were mounted on an articulator which was programmed according to the patients interocclusal records. The diagnosis was completed after evaluation of diagnostic casts which also revealed the mesial migration of maxillary and mandibular posterior teeth (Fig 1c). Occlusal problems identified were lack of posterior disclusion, molar contact in protrusion, molar contact in lateral excursions, increased overjet, non existing overbite and attrition of functional cusps of natural teeth in both arches. A multidisciplinary approach towards treatment plan was mandatory and it included opinion from an orthodontist, oral surgeon and periodontologist. Considering the age of the patient the treatment plan suggested to the patient included surgical correction of the open bite followed by orthodontic and prosthodontic treatment to which she consented. She rejected alternative treatment plan of a fixed partial denture in relation to missing left first molar without correction of her appearance.
After a thorough medical check, the patient underwent orthognathic surgery in which the maxilla was exposed using the standard sublabial vestibular incision and subperiosteral dissection (Fig 2a). A horizontal saw cut was made at the Le Fort level from the zygomatic buttress forward to the piriform aperture (Fig 2b) following which a back cut was performed from the buttress to the pterygomaxillary fissure. The amount of bone that was removed was in accordance with the preoperative planning for the amount of bone to be removed. Differential posterior impaction of the maxilla was achieved by removal of a tapering bone strip of appropriate width (Fig 2c). The maxilla was thus advanced forward and downward at a level indicated by the natural teeth following which multiple miniplates (Canwell medical limited) were fixed to the maxilla (Fig 2d). The area was cleaned and the incision was sutured following which the patient was put under post surgical care for a period of one week (Fig 2e). The patient responded well to the surgery and is in line for the orthodontic treatment, after which the respective definitive prosthodontic treatment will be done. An interim partial denture is currently in use by her.

\section{Discussion}

It is significant to understand the etiology of every malocclusion and dentofacial discrepancies in all dimensions since the choice of treatment has a long term effect on its potential stability. AOB shares the same principles in choosing a treatment strategy and conventionally three principal surgical methods are used to correct AOB. These include an isolated mandibular surgery, a segmental impaction of posterior maxilla and differential posterior impaction of osteotomized maxilla (Le fort 1 osteotomy). ${ }^{7-9}$ The latter option was chosen for this case since it allowed autorotation of the mandible posteriorly. AOB is not a common problem, but can be challenging for occlusal rehabilitations. Firstly, this case report is unique in the fact that a patient underwent such an exhaustive pre prosthetic treatment for a fixed partial denture. One has to understand the psychological influence of such 
dentofacial deformity to understand the patient's conviction for the treatment. The patient was young and had been suffering from the impaired facial aesthetics as a result of skeletal deformity. Marriage could be a reason for motivating her to undergo a lengthy treatment protocol. The patient was thoroughly educated about her dental condition, especially the role of anterior teeth in developing the cuspal anatomy of posterior teeth. Future impacts of the present condition on the long term retention of teeth were, explained in detail to the patient.
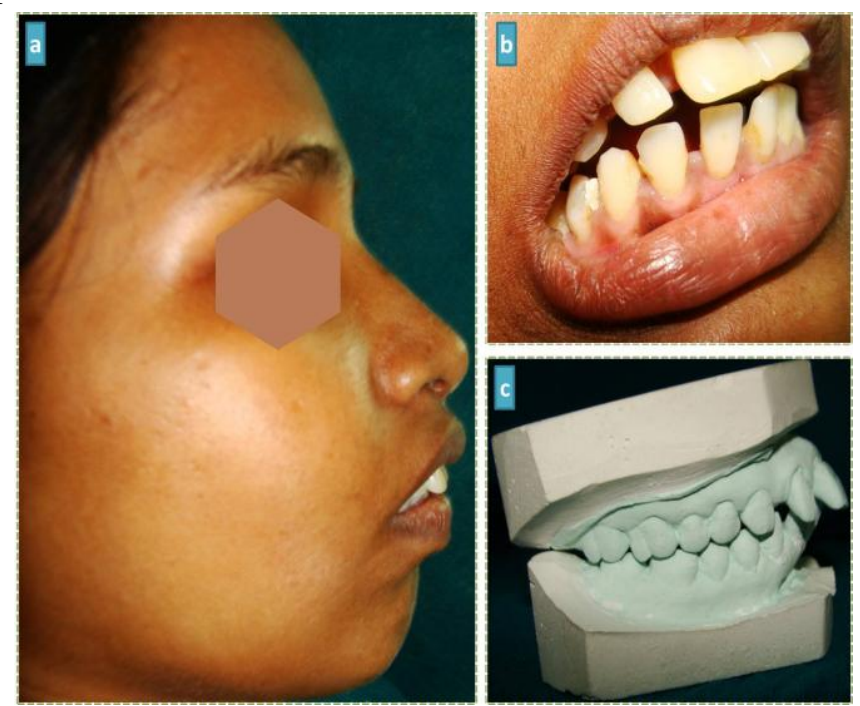

Figure 1: (A) Extra oral lateral view (B) ineffective anterior guidance $(C)$ Diagnostic cast showing extent of overjet and overbite deformity

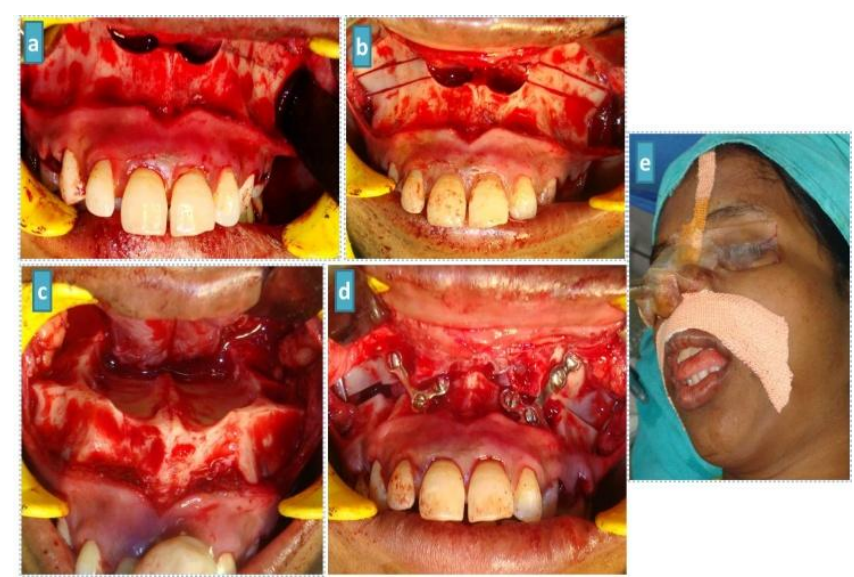

Figure 2: (A) Exposed maxilla (B) Horizontal cut (C) removal of bone (D) Placement of miniplates at the correcting skeletal position of the maxilla (E) Patient during anesthetic recovery with improved maxillary position.
Multidisciplinary management of $\mathrm{AOB}$ cases is mandatory since it involves a major surgery and the treatment strategy is dependent on the main etiology. Long term periodontal problems need to be established in a sequential way for better patient motivation. Cephalometric analysis by orthodontist should be a part of diagnostic tool to develop a surgical strategy.

\section{Conclusion}

An extensive orthognathic surgery as part of preprosthetic mouth preparation is rarely done however in a young patient the aesthetic impairment associated with skeletal malocclusion seems to be a huge motivating factor for which studies should be done.

\section{Acknowledgements}

The authors would like to acknowledge the staff of the department of oral surgery, orthodontia and periodontology for their valued opinions during the treatment of this case.

\section{References}

1. Sassouni V. A classification of skeletal facial types. Am J Orthod 1969;55:109- 23.

2. Naini FB, editor. The maxilla and midface. In: Facial Aesthetics: Concepts and Clinical Diagnosis. Oxford: Wiley- Blackwell; 2011

3. Naini FB, Stewart S, Gill DS. Surgical correction of anterior open bite: Differential posterior maxillary impaction. In: Naini FB, Gill DS, editors. Orthognathic Surgery: Principles, Planning and Practice. Oxford: Wiley- Blackwell; 2017.

4. Teittinen M, Tuovinen V, Tammela L, Schatzle M, Peltomaki T. Long-term stability of anterior open bite closure corrected by surgical-orthodontic treatment. Eur J Orthod. 2012; 34: 238-243.

5. Löe H, Theilade E, Jensen SB (1965) Experimental gingivitis in man. $\mathbf{J}$ Periodontol 36:177-187. 
6. Gibbons RJ, van Houte J (1973) On the formation of dental plaques. J Periodontol 44: 347-360.

7. Naini FB, Gill DS, editors. Orthognathic surgery: Preliminary consideration. In: Orthognathic Surgery: Principles, Planning and Practice. Oxford: Wiley- Blackwell; 2017.

8. Reyneke J, Ferretti C. Surgical correction of skeletal anterior open bite: Segmental maxillary surgery. In: Naini FB, Gill DS, editors. Orthognathic Surgery: Principles, Planning and Practice.Oxford: Wiley- Blackwell; 2017.

9. Bloomquist D, Joondeph D. Surgical treatment of anterior open bite with mandibular osteotomies. In: Naini FB, Gill DS, editors. Orthognathic Surgery: Principles, Planning and Practice. Oxford:Wiley- Blackwell; 2017. 